\title{
Transmission Capacity as a Common-Pool Resource: The Case of Gas Interconnector Capacity
}

\author{
Reinier Verhoog ${ }^{1}$, Amineh Ghorbani², Gerard P.J. Dijkema ${ }^{3}$ and Zofia Lukszo² \\ ${ }^{1}$ College of Management of Technology, Swiss Federal Institute of Technology Lausanne, Switzerland \\ ${ }^{2}$ Faculty of Technology, Policy and Management, Delft University of Technology, The Netherlands \\ ${ }^{3}$ Energy and Sustainability Research Institute Groningen, University of Groningen, The Netherlands
}

\begin{abstract}
We investigated the very real problem of congestion at gas interconnectors. Instead of suggesting further incremental change to the European regulation in force to remedy congestion problems, we took a step back and consider gas interconnectors as a Common-Pool Resource (CPR). We suggest to wait and see what institutions the shippers let emerge to govern and manage interconnector capacity.

To explore this idea, we developed a model to simulate the possible emergence of institutions that would coordinate the shippers and help overcome congestion. We simulate 40 shippers at the Dutch and Belgian interconnectors and allow them to autonomously book capacity. Agents can learn over time to improve their behaviour and coordinate with each other to collectively define a new institution in the system. The main simulator indicators are the observed booking behaviour, agent profits and emerging institutions. We present and discuss preliminary results from a set of simulation runs.
\end{abstract}

Keywords: Agent-Based Modelling, Common-Pool Resources, Congestion Management, Emerging Institutions, Gas Interconnectors

\section{INTRODUCTION}

Liberalization of the European gas sector has caused an increase in the number of active market parties, which increases the complexity of delivering ancillary services, such as managing the grid pressure (balance). Increasingly, control is becoming distributed amongst market players, which results in a situation where no single player alone is delivering the balancing service. Ultimately, the TSO is responsible for the system balance, but we see a shift to decentralized market-based balancing.

A condition for decentralized market-based balancing is a high traded-volume (liquidity) on gas hubs such as the Dutch Title Transfer Facility (TTF) which introduced a within-day market in June $2014^{1}$

\footnotetext{
1 GTS. Within Day Blancing Action (WDBA) as of 3 June 2014. (2014). at <http://www.gasunietransportservices.nl/en/ transportinformation/about-balancing/within-day-balancing-action-wdba-vanaf-3-juni-2014>

2 GTS. Dataport. at <http://www.gasunietransportservices.nl/en/transportinformation/dataport>

3 GTS. Transport insights 2012. (2013). at <http://www.gasunietransportservices.nl/uploads/download/cd8f8651-efc6-424a-b564ab3f89ac0884>

4 Harris, D. \& Lapuerta, C. Gas market integration via implicit allocation: Feasibility from the North-West European gas market perspective. (2012). at <http://www.acer.europa.eu/Gas/Regional_Intiatives/North_West_GRI/Documents/The Brattle Group gas implicit allocation report.pdf>
} 
. Cross border gas-trading increases the liquidity of gas hubs and can lower the costs of balancing if there is a price difference between hubs, and if there is transmission capacity available. However, interconnectors between the Netherlands and Belgium can be congested, meaning that there is no capacity available to accommodate crossborder gas flows².

The congestion may be caused by shippers who book more capacity than that they use in practice. They do this because gas demand depends heavily on ambient temperature, which is unpredictable, and because they must respect safety margins. Furthermore, booked capacity has a value, because it gives shippers the option to freely trade on various connected hubs and leverage price differences ${ }^{3}$. When the booked capacity increases, so do revenues for the transmission system operator (TSO). The ensuing congestion, however, requires capacity expansion or other congestion management measures. Improving the coordination between capacity booking and gas allocation will result in better interconnector investment signals ${ }^{4}$. The latest Network Code, Regulation (EU) No 984/2013, focusses on reducing interconnector congestion through congestion management measures.

An overview of congestion management measures is given in the study done by The Brattle Group ${ }^{4}$. A qualitative description of likely effects is available for the congestion management measures, but a quantitative assessment of a practical case is currently missing. Furthermore, it is unclear how these measures will perform on the borders between Member States where they are subject to different conditions, institutions and network characteristics. The question then is 'to what extent shipper behaviour can be influenced to reduce congestion at border points'.

Institutions are a means to govern behaviour. Since interconnector capacity can be considered a shared resource that maybe overused, which leads to congestion problems, one possibility to define effective institutions is to apply solutions provided for the management of Common-Pool Resource (CPR) systems. Therefore, in this paper, we explore the applicability of CPR problems as an alternative to top-down coordination of gas interconnectors. The emergence of endogenous institutions has proven ${ }^{5-7}$ to be successful at avoiding Hardin's Tragedy of the Commons ${ }^{8}$. Using agent-based modelling (ABM), it is possible to replicate emerging institutions in CPR systems, which are commonly observed in the field ${ }^{9}$. ABM is well suited to study the coordination between agents in CPR systems by means of virtual experiments ${ }^{10,11}$.

The paper is structured as follows. Section 2 gives a definition of CPR and argues the applicability to interconnector capacity. Section 3 presents our modelling and simulation approach. The simulation results are presented in section 4. The paper is concluded in section 5.

\section{INTERCONNECTOR CAPACITY AS A COMMON-POOL RESOURCE}

CPR are characterized by finite quantities, non-exclusiveness and rivalry amongst their users. Since it is difficult or costly to exclude users from consuming the resource ${ }^{12}$ it is likely that valuable resources are overexploited, or even destroyed in the process. Consumption by one user lowers the availability of the resource for other users. High value CPR are attractive targets of consumption, and consumption by one user is likely to cause negative externalities for other users ${ }^{13}$.

5 Anderies, J.M. \& Janssen, M. A. Sustaining the commons. Tempe (Center for the Study of Institutional Diversity, 2013).

6 Ostrom, E. Governing the commons: The evolution of institutions for collective action. (Cambridge university press, 1990).

7 Ostrom, E. Understanding institutional diversity. (Princeton University Press, 2009).

8 Hardin, G. The tragedy of the commons. Science (80-. ). 162, 1243-1248 (1968).

9 Ghorbani, A. \& Bravo, G. The Emergence of Institutions for the Management of the Commons. in Soc. Simul. Conf. (SSC14), Barcelona, 1-5th Sept. 2014 (2014).

10 Bravo, G., Squazzoni, F. \& Boero, R. Trust and partner selection in social networks: An experimentally grounded model. Soc. Networks 34, 481-492 (2012).

11 Poteete, A. R., Janssen, M. A. \& Ostrom, E. Working together: collective action, the commons, and multiple methods in practice. (Princeton University Press, 2010).

12 Ostrom, E., Gardner, R. \& Walker, J. Rules, games, and common-pool resources. (University of Michigan Press, 1994).

13 Ostrom, E. Reformulating the commons. Swiss Polit. Sci. Rev. 6, 29-52 (2000).

14 Finger, M.P., Groenewegen, J. P. M. \& Künneke, R. W. The Quest for Coherence Between Technology and Institutions in Infrastructures. J. Netw. Ind. 6, 227-259 (2005).

15 Feeny, D., Hanna, S., Mcevoy, A. F. \& Mcevoy, F. Questioning the assumptions of the "Tragedy of the the Commons" Model of Fisheries. Land Econ. 187-205 (1996). 
Apart from classical examples like forests, fisheries and water basins, CPR also include man-made systems such as mainframe computers and the Internet ${ }^{13}$. We argue that transmission capacity at gas interconnectors can be seen as an example of CPR. Firstly, the resource is finite and is determined by the physical capacity of the interconnector pipelines. Secondly, the booking of capacity by one shipper lowers the capacity available for other shippers. Thirdly, over-booking causes negative externalities as the interconnector can become congested. Fourthly, it is not allowed for TSOs to restrict access to the resource due to the third party access-requirements in Europe; thus licensed shippers are free to procure the capacity they deem necessary. Finally, while there are costs associated with the booking of capacity, these costs are too low to deter shippers from overbooking. These characteristics lead to problems with two essential infrastructure properties: capacity management and interconnection ${ }^{14}$.

Like most studied CPR systems ${ }^{15}$, gas interconnectors can be considered a relatively simple physical system. However, interconnectors are complex socio-technical systems that comprise many stakeholders, institutions and technical artefacts. Furthermore, interconnectors are the link between two, often very different, national gas systems. In order to study the overuse of interconnectors as a CPR problem we have made a number of assumptions that are common for CPR studies:

1. Interconnector capacity, expressed in $\mathrm{kWh}$, is a finite resource that can only be increased by physical expansion of the interconnector pipelines.

2. Shippers are homogeneous in their demand, capability to procure capacity, and discount rates.

3. Shippers focus on maximizing their short-term profits.

4. Shippers have complete (public) information about the availability of interconnector capacity2.

5. All shippers have open access to book interconnector capacity.3

Such a simplification would likely lead to a system representation able to reproduce the observed overuse of transmission capacity. Due to the self-interest of shippers we would observe a tragedy of the commons ${ }^{8}$. In line with this observation we see that policy makers are imposing institutions, such as congestion management measures, to change the behaviour of the shippers.

However, other complex CPR systems have demonstrated the ability to achieve better social behaviour through coordination between users ${ }^{16-19}$. It is not unlikely that coordination between shippers can lead to reduced congestion at interconnectors. In fact, interconnectors have favourable attributes that stimulate self-governance ${ }^{20}$ :

6. Interconnector capacity cannot deteriorate because of overuse, meaning that there is no point beyond which selfgovernance is senseless.

7. Interconnector capacity is monitored and made available to shippers in near-real time ${ }^{21}$.

8. Available interconnector capacity is relatively predictable due to long-term capacity contracts ${ }^{3}$.

9. Interconnectors are part of larger natural gas systems, and can be seen as one of the many entry- or exit-points with active shippers. As a result, the spatial extent of interconnectors is limited.

Shippers with cross-border gas flows are dependent on the interconnector capacity. Thus, there is an incentive to coordinate between shippers. However, overbooking is currently a cheap risk-mitigating strategy against penalties that might hamper coordination.

There is much research on endogenous CPR institutions that emerge with time, for example, in the case of smallto medium-sized irrigation systems ${ }^{13}$. As gas interconnectors can be seen as CPR, new institutions around them may emerge, too. This is the more interesting, as the current gas connector system has only been opened up to competing shippers between 2000 and 2005 as a result of the liberalization. Since then the system has seen many

16 Cordell, J. A Sea of Small Boats. (Cultural Survival, 1989).

17 Wade, R. Village Republics: Economic Conditions for Collective Action in South India. (ICS Press, 1994).

18 Ruddle, K. \& Johannes, R. The Traditional Knowledge and Management of Coastal Systems in Asia and the Pacific. (UNESCO, 1985).

19 Sengupta, N. Managing Common Property: Irrigation in India and the Philippines. (Sage, 1991).

20 Ostrom, E., Burger, J., Field, C. B., Norgaard, R. B. \& Policansky, D. Revisiting the commons: local lessons, global challenges. Science (80-. ). 284, 278-282 (1999).

21 GTS. Entry-/Exitcapacity. at <http://www.gasunietransportservices.nl/en/products-services/entry-exitcapacity> 
institutional changes, with the latest changes in 2014 when capacity auctions replaced the first-come-first-served system. However, the emergence of institutions may require a period spanning years or decades.

To learn about emerging institutions, we are not forced to wait. We can build models to play out and simulate multiple futures, and study by what patterns institutions would emerge under what conditions. We formulate the following additional assumptions to extend the classical study of CPR:

10. Shippers can make an effort to change their behaviour and prevent the over-booking of interconnector capacity to reduce the external effects of congestion.

11. Shippers can communicate and coordinate, allowing for the selection (emergence) of institutions within the system to which the shippers will comply.

\section{MODELLING EMERGING INSTITUTIONS AT GAS INTERCONNECTORS}

When studying the coordination between shippers at interconnectors there are two issues that have to be overcome. Firstly, preliminary data analysis of open interconnector data does not seem to indicate coordination between shippers and it is not known when such coordination can be expected to occur. Secondly, observations can take a long time to complete, which is time consuming and also makes it difficult to control the external variables of the experiment. ABM is suitable to simulate coordination at interconnectors, because agents have the following attributes 22 :

- Autonomy; agents operate individually and act in their self-interest. Shippers have shown to overuse interconnector capacity when they act autonomously.

- Co-operation; agents can interact with one another. By sharing a common interface the agents can exchange information about their actions and norms for example.

- Learning; agents can learn from their actions, and those of other agents, to improve their future performance. Learning is important for the emergence of new institutions.

An existing model for simulating emergence of institutions for CPR problems is used ${ }^{9}$. This evolutionary model has already shown that emerging institutions through collective intelligence of agents can help in managing CPRs. The model is implemented using NetLogo 5.0.323.

\section{Model description}

The model primarily focusses on the booking behaviour of shippers on the interconnectors from the Netherlands to Belgium. In total there is an estimated physical interconnector capacity of 110 million kWh, based on 2011 open capacity data ${ }^{2}$. The capacity is assumed to be fixed during the simulation and is reset every day (model tick), because the physical capacity does not deteriorate when used.

We simulate 40 heterogeneous shippers (agents) that represent the active shippers. Each day the shipper is assigned a random gas demand, based on the aggregated gas demand per day in $2011^{2}$. Every day the shippers book new capacity, which is a simplification of the real-world situation in which there are yearly, quarterly, monthly and daily capacity auctions. This allows us to simulate shipper learning and emerging institutions more rapidly, but can overestimate effects on booking behaviour.

The goal of the shippers is to autonomously book interconnector capacity and to maximize their short-term profits. Profits are maximized by acquiring capacity, because it avoids penalties for being out of balance and the value of capacity can be higher than its market price. Initially the shippers choose a random strategy, but over time they can change their booking behaviour as follows:

- Selection; shippers learn from their own strategies and select new strategies that give a higher payoff. Shippers can also copy the behaviour of others who are using better strategies. Selection is expected to result in shippers avoiding penalties and acquiring as much capacity as possible.

2222 Nwana, H. S. Software agents: an overview. Knowl. Eng. Rev. 11, $205-244$ (1996).

23 Wilensky, U. NetLogo. (1999). at <http://ccl.northwestern.edu/netlogo> 
- Coordination; agents can coordinate by establishing a new capacity booking institution if the emergence of institutions is enabled. An institution will emerge after a certain period of time if a threshold of shippers is reached that use the same strategy. If such an institution has emerged the shippers have to comply, as we have not included non-compliance in the current model.

\section{Experimental setup}

Due to the recent introduction of capacity auctions it is unclear how these auctions will perform and what their impact on the booking behaviour of shippers will be. Well performing auctions are expected to result in capacity prices that are closer to the value that shippers assign to capacity, which is expected to reduce over-booking. On the other hand, if the auctions do not perform well it is expected that prices will not increase enough. It should be noted that we do not simulate the auctioning processes, but rather assume that shippers assign a higher value to capacity when bidding.

Furthermore, we are interested in exploring the impact of coordination on the booking behaviour of shippers. A new institution is observed when both the time threshold (50 ticks) and shared shipper strategy threshold (50\%) are satisfied. This results in four virtual experiments, summarized in table 1.

Table 1 - Summary of scenarios

\begin{tabular}{|c|c|c|c|c|}
\hline \# & Auction & Coordination & Objective & Expected outcome \\
\hline 1 & No & No & Replicate 2011 observations & $\begin{array}{l}\text { Over-booking, but capacity is re-allocated } \\
\text { through learning }\end{array}$ \\
\hline 2 & Yes & No & $\begin{array}{l}\text { Evaluate the effect of the new } \\
\text { auctions introduced in } 2014\end{array}$ & $\begin{array}{l}\text { Reduced over-booking, as there is little } \\
\text { additional value in acquiring capacity }\end{array}$ \\
\hline 3 & No & Yes & $\begin{array}{l}\text { Observe emerging institutions } \\
\text { compared to the } 2011 \text { situation }\end{array}$ & $\begin{array}{l}\text { Emergence of an institution to over-book, } \\
\text { as this is the status quo }\end{array}$ \\
\hline 4 & Yes & Yes & $\begin{array}{l}\text { Observe emerging institutions } \\
\text { compared to the } 2014 \text { situation }\end{array}$ & $\begin{array}{l}\text { Emergence of an institution to book what } \\
\text { is necessary to avoid penalties }\end{array}$ \\
\hline
\end{tabular}

\section{RESULTS AND INSIGHTS}

In this section we present the preliminary results, from the first version of our gas interconnector model. Please note that these are initial results, which are based on a limited set of runs. Here we present the aggregated results of 200 model runs, to get a first idea of likely behaviour under different scenarios and to observe the collective behaviour of shippers.

Experiment 1. As expected, we observe that the shippers are over-booking the interconnector capacity. What we observe here could be labelled an institution, since most shippers are behaving in the same way. Even though we can observe attempts by shippers to redistribute the capacity amongst each other to avoid penalties we see that this is futile in the long run. Capacity is simply too valuable for agents to not acquire. As a result of the over-booking, there are shippers who receive large penalties, which is reflected in the decreasing average money of the shippers.
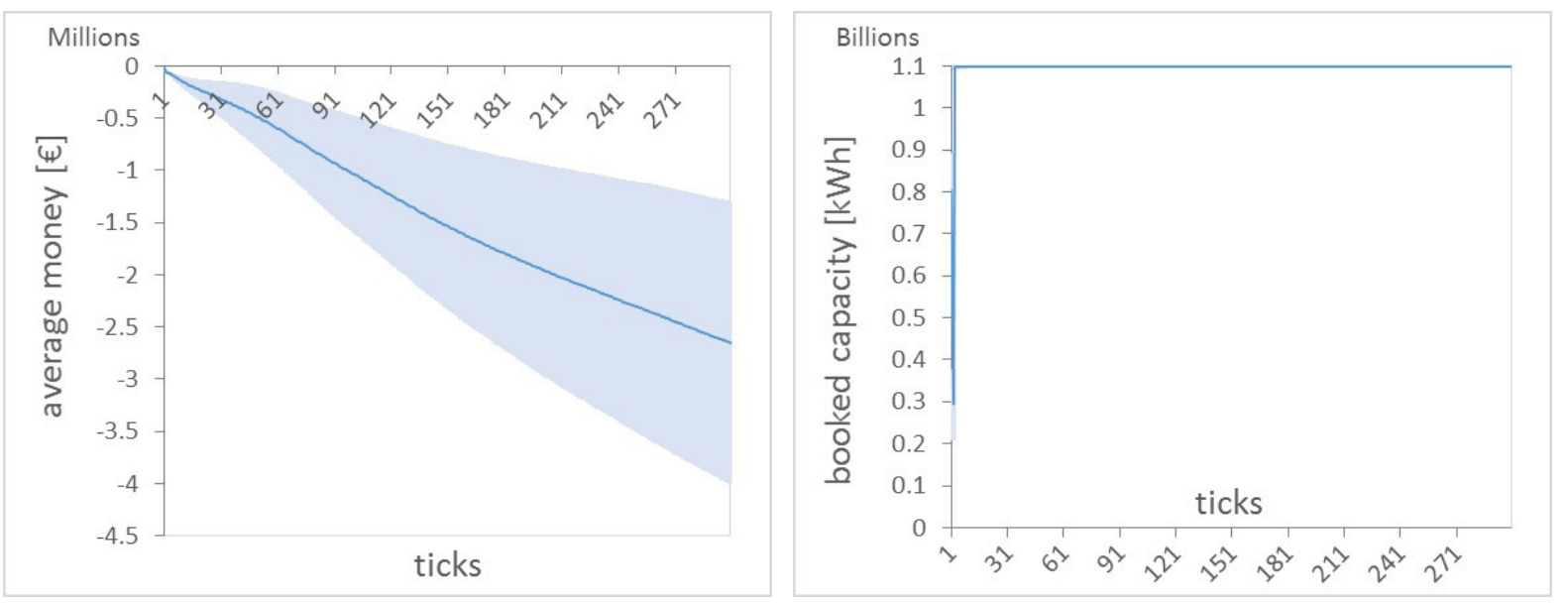
Figures 1a and 1b - Economic performance and booking behaviour of shippers under scenario 1.

Experiment 2. When the value of capacity is decreased we can see that shippers learn over time to adjust their booking behaviour. There is a trend towards booking less capacity and shippers attempt to avoid penalties. In this experiment the behaviour of shippers is much more chaotic, as a result of the changing gas demand due to exogenous factors such as the weather. Interestingly, while capacity is more expensive, the losses of shippers are lower than they are in the first scenario. This is due to the fact that there is little to no congestion on the border point, allowing shippers to avoid penalties.
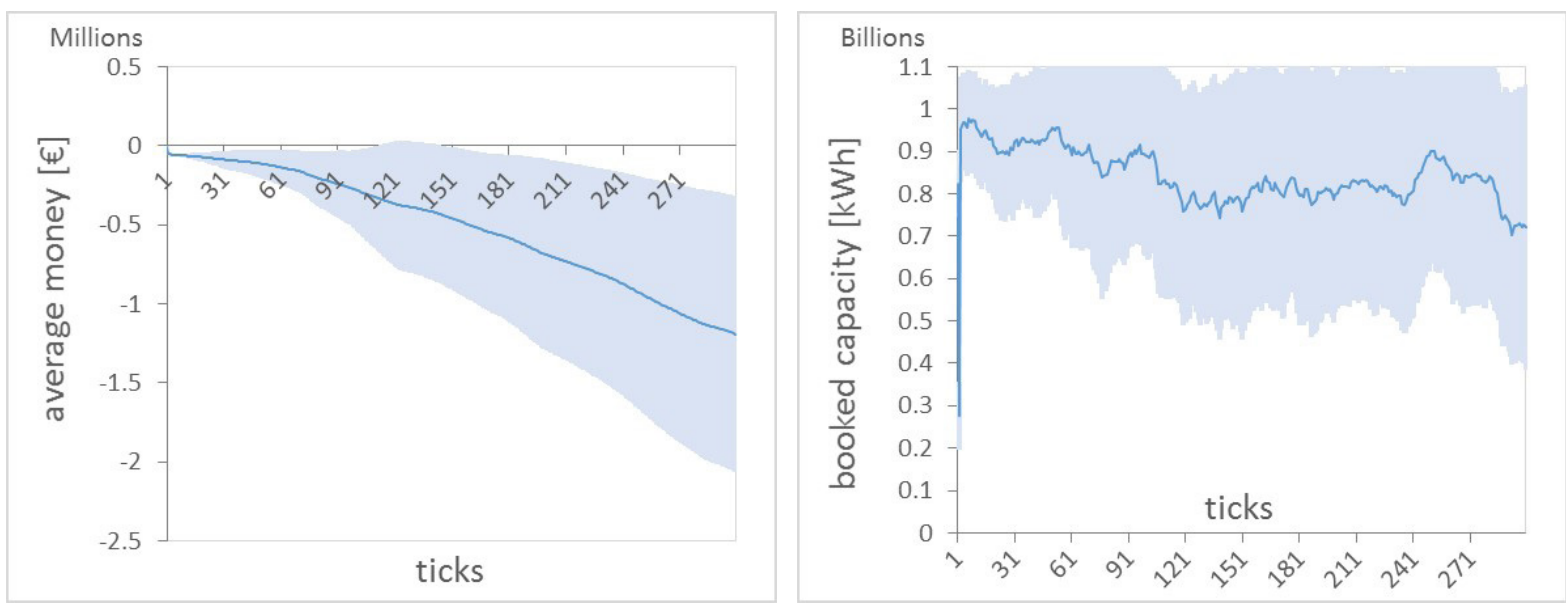

Figures 2a and 2b - Economic performance and booking behaviour of shippers under scenario 2.

Experiment 3. We observe that an institution to over-book the interconnector capacity emerges even when there are agents making losses. This leads us to believe that there are more shippers who are profiting from over-booking than there are shippers receiving a penalty. The emerging institution actually has an adverse effect in this situation, because it reinforces the over-booking behaviour and eliminates the ability for agents to learn and redistribute resources. The shippers that we have implemented are only self-interested and are unable to assess long-term payoffs. With this current model version, we cannot expect to observe more complex coordination between shippers.
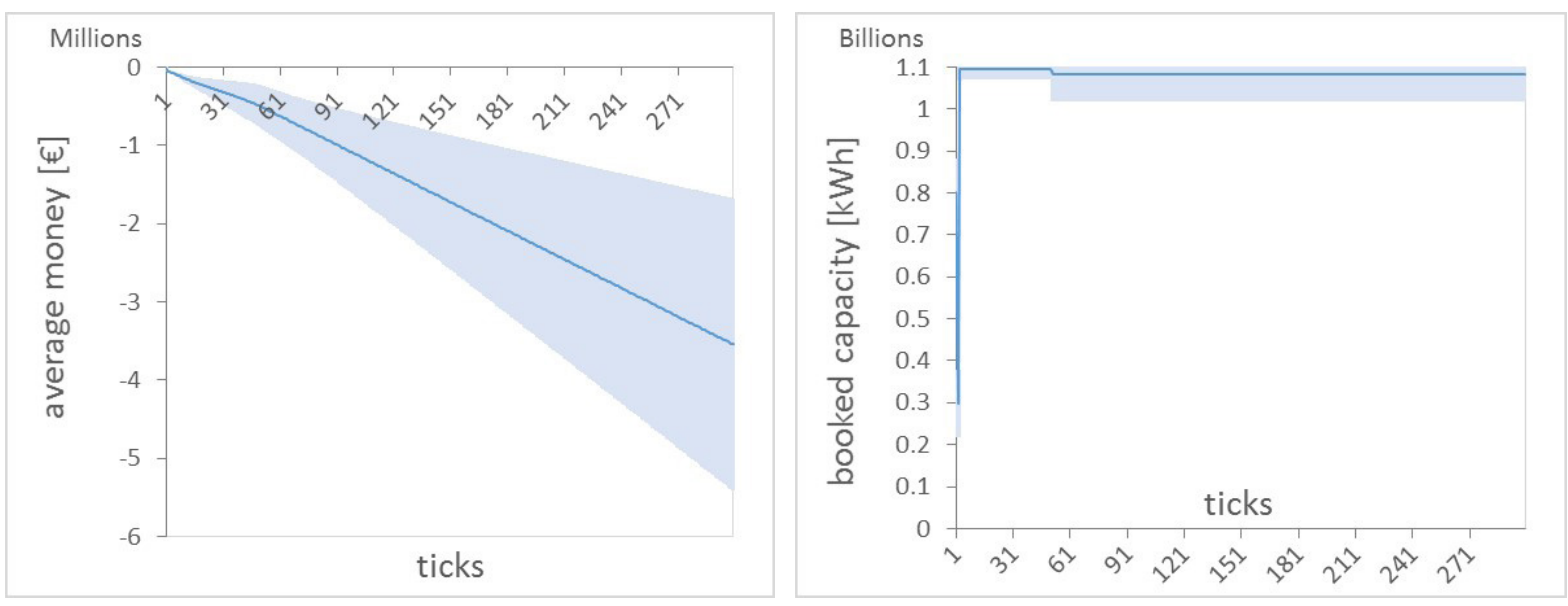

Figures 3a and 3b - Economic performance and booking behaviour of shippers under scenario 3.

Experiment 4. As expected, an institution emerges under which there is less-overbooking due to the increased capacity price. Similarly to scenario 2 the shippers can avoid penalties in most cases. As a result of the short-term focus of our shipper agents we see that they often arrive at an institution where they book more than they need to avoid the penalty. The learning effect, before the institution emerges, makes them risk-averse due to the high penalty associated with having too little capacity. 


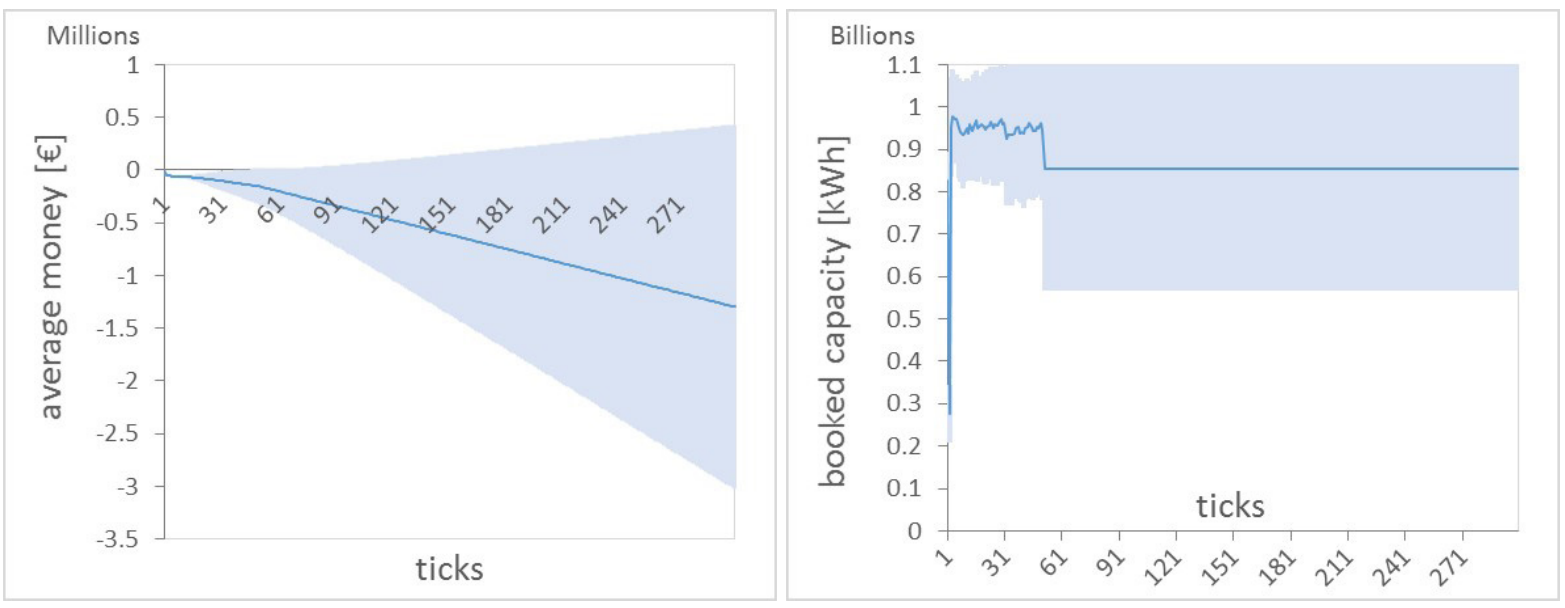

Figures 4a and 4b - Economic performance and booking behaviour of shippers under scenario 4.

\section{CONCLUSION}

In this paper we investigated the problem of congestion at gas interconnectors. Rather than suggesting further incremental modifications of the European regulations in force to remedy congestions, we took a step back. By considering gas interconnectors as a CPR, we realize that rather than having the EU introduce more detailed regulation, we suggest everyone to wait and see what institutions the shippers allow to emerge to govern and manage interconnector capacity.

To explore the implications of a wait and see approach, we developed a model to simulate the possible emergence of institutions that would coordinate the shippers and help overcome congestion. We simulate 40 shippers at the Dutch and Belgian interconnectors and allow them to autonomously book capacity. Agent can learn over time to improve their behaviour and coordinate with each other to collectively define a new institution in the system. The main simulator indicators are the observed institutions for booking interconnector capacity and shipper profits.

First model results indicate that simple agents are likely to reinforce the currently observed behaviour at interconnectors when they are allowed to coordinate. Their short-term focus leads to the emergence of institutions which are not optimal, and which are hard to get out of. This observation provides a new perspective on the observed over-booking in 2011, because it could be the case that real-world shippers have already coordinated in the past and are stuck in an inefficient institution.

Of course, more research, testing and development of the model is needed, but already we can give the following points to discuss:

- If simple (myopic) agents are able to reproduce the observed behaviour at interconnectors, it would be interesting to explore the institutions that more complex agents allow to emerge.

- The question remains whether TSOs need to implement congestion management measures. Preliminary results indicate that auctions can reduce congestion. This topic deserves more attention with efforts to realistically model capacity auctions.

- It remains unknown why the perceived value of capacity is higher than its current market price. Further research into the driving forces behind the value of interconnector capacity is advised.

\section{ACKNOWLEDGEMENTS}

This research has been financed by a grant of the Energy Delta Gas Research (EDGaR) program, project A1 Understanding gas sector intra- and inter-market interactions \& project B2 - TransGasID. EDGaR is co-financed by the Northern Netherlands Provinces, the European Fund for Regional Development, the Ministry of Economic Affairs and the Province of Groningen. 